\title{
Laparoscopic Distal Splenorenal Anastomosis
}

\author{
Dzidzava II ${ }^{1 *}$, Kotiv BN ${ }^{1}$, Onnicev IE ${ }^{1}$, Soldatov \\ SA$^{1}$, Smorodskiy AV ${ }^{1}$, Shevcov SV $^{1}$, Bugaev SA ${ }^{1,2}$ \\ and Apollonov $\mathbf{A A}^{1}$ \\ ${ }^{1}$ Department of Hospital Surgery, Military Medical \\ Academy named after S.M. Kirov, St. Petersburg, Russia \\ ${ }^{2}$ A.V. Vishnevsky National Medical Research Center of \\ Surgery, Moscow, Russia \\ *Corresponding author: Ilya Igorevich Dzidzava, \\ Department of Hospital Surgery, Military Medical \\ Academy named after S.M. Kirova, Acad. Lebedeva, 6, St. \\ Petersburg, 194044, Russia
}

Received: May 19, 2021; Accepted: June 09, 2021; Published: J une 16, 2021

\section{Abstract}

Introduction: Esophagogastric bleeding is the most formidable complication of the portal hypertension syndrome. At acute bleeding from varicose veins of the esophagus and stomach, mortality reaches 40 to $50 \%$ and is accompanied with the high risk of early hemorrhage recurrence in $30-50 \%$ of survivors. Portosystemic shunt surgery provides for radical decompression of the portal vein system and reliably prevent hemorrhage recurrence.

Purpose: To assess the possibility and efficacy of the Distal Splenorenal Anastomosis (DSRA) with a minimally invasive laparoscopic approach.

Methods: The study included 28 patients with portal hypertension syndrome who underwent laparoscopic DSRA. By the Child-Pugh scale, class A was $42.9 \%$, class B $-57.1 \%$. The indication for surgical decompression of the portal system was the ineffectiveness of repeated sessions of endoscopic ligation with recurrence of varicose veins of the esophagus (21.5\%) and/or bleeding from them $(46.4 \%)$ or the presence of varicose veins of the stomach $(32.1 \%)$.

Results: Mean surgery time was $294 \pm 86$ minutes. The maximum blood loss was $211 \pm 55 \mathrm{ml}$. The access conversion was performed in $10.7 \%$ of cases. In the postoperative period, the patients were in ICU for 1-2 days. The hospital stay and in-patients treatment duration was $9.4 \pm 2.5$ days. Both in the early and in the long-term follow-up, there were no cases of gastroesophageal bleeding and shunt thrombosis. The portosystemic encephalopathy developed in $12 \%$ of cases. The surgical decompression of the portal system was featured by a decrease in the degree of esophagus varication in the long-term period. The maximum follow-up period was 46 months.

Conclusion: Minimally invasive laparoscopic DSRA in patients with portal hypertension syndrome is a possible, safe and effective alternative treatment option.

Keywords: Portal hypertension; Bleeding from varicose veins of the esophagus; Portocaval shunt; Distal splenorenal anastomosis

\section{Introduction}

Esophagogastric bleeding is the most formidable complication of portal hypertension syndrome. Mortality in acute bleeding from Varicose Veins (VV) of the esophagus and stomach reaches 40 to $50 \%$ with a high risk of early hemorrhage recurrence in $30-50 \%$ of survivors. With the development of modern endoscopic and surgical methods of hemostasis, mortality in gastroesophageal bleeding of portal genesis decreased to $10-20 \%$ when treated in specialized hospitals [1-8].

The method of choice for the treatment of acute portal bleeding and the most frequent method of its prevention is endoscopic ligation of the esophagus VVs. In case it is ineffective or progressing of VVs of the stomach, more aggressive surgical methods come into play: portocaval anastomoses and surgical azygoportal disconnection [6-8]. Portosystemic shunting, providing radical decompression of the portal vein system, is considered more preferable. Among these, most common are Transjugular Intrahepatic Portosystemic Shunting (TIPSS) and Distal Splenorenal Anastomosis (DSRA). The indisputable advantage of TIPSS is its low invasiveness. DSRA is a more traumatic intervention, although it is accompanied by a lower incidence of shunt patency and post-shunt encephalopathy [4,5,911].

\section{Purpose}

To assess the possibility and efficacy of the Distal Splenorenal Anastomosis (DSRA) with a minimally invasive laparoscopic approach.

\section{Materials and Methods}

The study included 28 patients with portal hypertension syndrome in which DSRA was formed by laparoscopic access in the clinic of hospital surgery of S.M. Kirov Military Medical Academy. In the overwhelming majority of cases (93\%), the cause of portal hypertension was liver cirrhosis, while an increase in pressure in the portal vein system resulted from thrombosis and cavernous transformation of $\mathrm{v}$. portae with a passable splenic vein in two cases. The mean age of the patients was $46.1 \pm 9.8$.

Depending on the liver failure severity, the patients were distributed by Child-Pugh classification (1973) [12] as follows: class A - 12 (42.9\%), class B - 14 (57.1\%) cases. The severe thrombocytopenia occurred in $39.8 \%$ of cases.
Austin J Surg - Volume 8 Issue 3 - 2021

ISSN : 2381-9030 | www.austinpublishing group.com

Dzidzava et al. @ All rights are reserved 
The degree of esophagus VV at fibroesophagastroscopy was assessed by K.J. Paquet's classification (1983) [13]; the stomach veins were evaluated according to P. Binmoeller's criteria (1996) [14]. The overwhelming majority of patients $(\mathrm{n}=26,92.9 \%)$ had III and IV grade esophagus VV. In two cases, the degree of varicose veins of the esophagus was assessed as II, though in these cases there was a pronounced dilatation of the veins of the gastric fundus. In general, the stomach VVs were diagnosed in $16(57.1 \%)$ patients, of which grade I - 7 (43.8\%), II - 5 (31.3\%), III - 4 (25\%) cases.

All patients took routine DSRA. The indication for surgical decompression of the portal system was the ineffectiveness of repeated sessions of endoscopic ligation with recurrence of varicose veins of the esophagus (21.5\%) and/or bleeding from them (46.4\%) or the presence of varicose veins of the stomach $(32.1 \%)$.

The functional state of the liver was assessed by traditional complex biochemical tests, portohepatic circulation parameters, data of clearance test with indocyanine green, and CT liver volumetry.

The hepatic encephalopathy was diagnosed on the basis of clinical and anamnestic data and by psychomotor number connection test. To classify the severity of reversible neuropsychiatric disorders, the grades from S.D. Podymova (2005) [15] were used. The clinical signs of encephalopathy were revealed in two patients.

The dynamics of changes in the VV of the esophagus and stomach was assessed with FEGDS data on days 14-21 after the operation, as well as in the long-term period, after 6 months.

The state of portohepatic circulation was studied using a complex ultrasound study (velocity and volume parameters of blood flow, pulsation and resistance indices) and computed tomographic angiography. Ultrasound examination in the modes of color Doppler mapping and pulsed Doppler sonography was performed in all patients at the stages of preoperative preparation, in the early postoperative (1-3-5 and 14-21 days) and in the remote (after 6 months) periods. CT angiography was performed in all cases of preoperative examination and at 6 months of the long-term period. At the same time, the topographic features of the surgical anatomy of the portal system and the left renal vein were determined. The state of the portal vein and the volume of the spleen were assessed. The variant of the anatomical norm of the vessels, the peculiarities of the location of venous collaterals and the presence of spontaneous portocaval anastomoses were determined. To optimize the surgical technique, the sizes and features of the interposition of the vessels (splenic, left renal veins) were determined.

The conditions for the possible formation of DSRA were considered the degree of hepatic insufficiency of Child-Pugh classes $\mathrm{A}$ and $\mathrm{B}$, satisfactory indices of the indocyanine green test (plasma elimination rate $>8 \% / \mathrm{min}$, residual concentration $15^{\prime}<34 \%$ ), liver volume according to CT volumetry $>1,300 \mathrm{ml}$, volumetric portal blood flow over $600 \mathrm{ml} / \mathrm{min}$, no pancreatitis and ascites in history, and the distance between the splenic and left renal veins not more than $3 \mathrm{~cm}$.

The digital data were statistically processed with SPSS 16.0 and Statistica 6.0 for Windows. The mean values and standard deviations, medians and interquartile intervals were determined. In the overwhelming majority of cases, nonparametric methods of

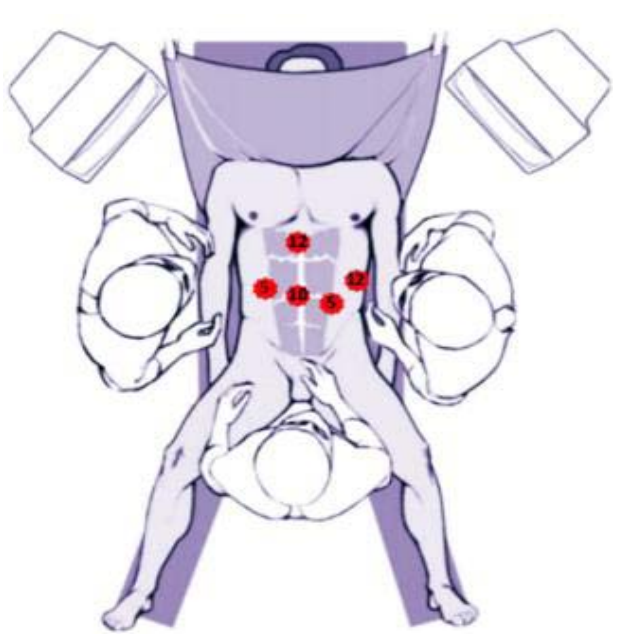

Figure 1: Surgical team and trocar placement layout.

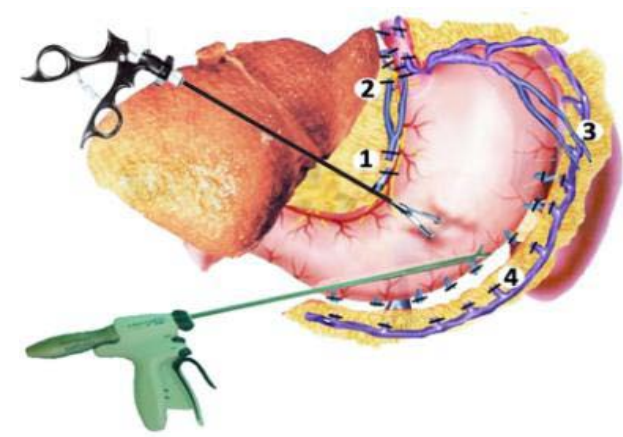

Figure 2: Scheme of laparoscopic gastric devascularization. The dissection of the branches of the left and right gastroepiploic veins (1 - left gastric vein, 2 - varicose veins of the paraesophageal zone, 3 - short stomach veins, 4 - left and right gastroepiploic veins).

statistical analysis were used. Comparison of two independent groups for one characteristic was performed with Mann-Whitney U test and Kolmogorov-Smirnov test. In a comparative analysis of dependent groups for one characteristic, the Wilcoxon test was used.

Results. The operations were performed under endotracheal anesthesia. The patient was in dorsal position with raised $\left(20^{\circ}\right)$ and right turned $\left(10^{\circ}\right)$ operating table head, and legs as far apart as possible. Two $\varnothing 12 \mathrm{~mm}$ trocars, one $\varnothing 10 \mathrm{~mm}$ trocar and two $\varnothing 5 \mathrm{~mm}$ trocars were installed (Figure 1).

After revision of the abdominal organs, assessment of the state of the liver and spleen, the degree of changes in the vessels of the portal vein system, a marginal liver biopsy was performed to histologically verify the diagnosis and determine the prognosis of the course of the underlying disease. Then the stomach was mobilized with ultrasound scissors along the greater curvature from the pyloric section with gastroepiploic vein and its tributaries clipped and transected (Figure 2). The short stomach veins were not transected. The mobilized stomach was sutured to the anterior abdominal wall, while the omental bursa and pancreatic capsule were opened along its entire length. To improve access to the pancreas and greater separation of the mesenteric and lienal venous areas, the lienocolic ligament was transected and the splenic flexure was mobilized. After that, the 


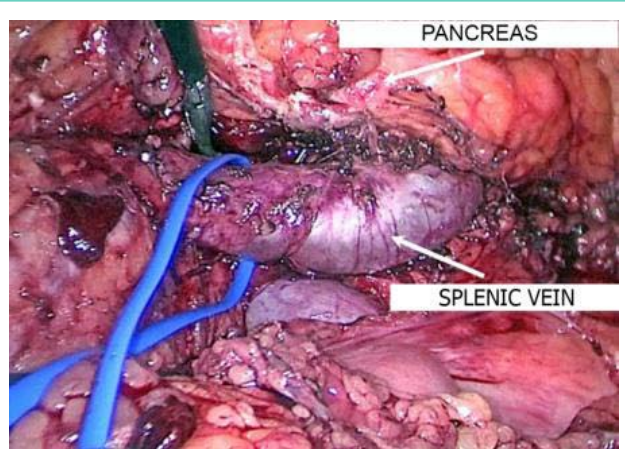

Figure 3: Intraoperative image. Isolation of the splenic vein and taking it on a holder.

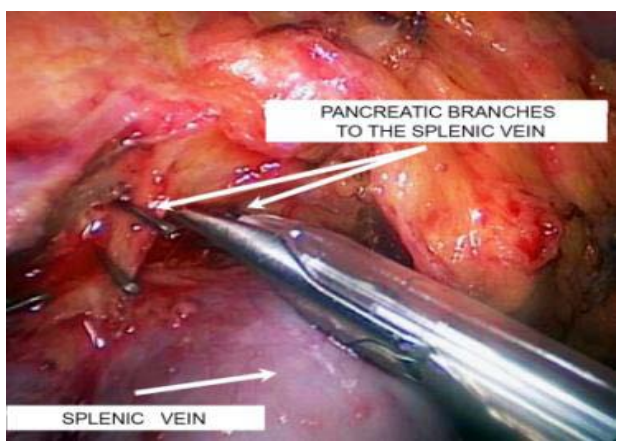

Figure 4: Intraoperative image. Isolation of the splenic vein. Clipping and transection of the pancreatic branches of the splenic vein.

pancreas was mobilized along its lower edge from the isthmus and superior mesenteric vein to the splenic hilum.

The splenic vein was exposed where it was best seen. The vein was mobilized along its entire length up to the place of confluence with the superior mesenteric vein. At this, the inferior and posterior surfaces of the vein were first dissected as free of branches. As the inferior mesenteric vein flows into v. lienalis, the former was clipped and dissected. In the area of confluence with v. mesenterica superior, the splenic vein was passed around and an elastic holder was put (Figure 3).

Next, the anterior and upper vein surfaces were isolated. The peculiarity of the mobilization of these walls is that pancreatic vein branches are always located in the area. This stage was the most difficult during the operation, since the pancreatic branches of the splenic vein are small and fragile, and their damage under portal hypertension leads to rather intense bleeding. Before transection of large pancreatic veins, they were clipped with a miniclipper and 2.5 $\mathrm{mm}$ long clips (Figure 4). In all cases, the aim was to achieve complete pancreatic disconnection, necessary for long-term preservation of the selectivity of the future splenorenal anastomosis, preservation of hepatopetal portal circulation, and prevention of post-shunt encephalopathy in the long term.

The second step was the isolation of the left renal vein. For this purpose, the parietal peritoneum was opened to the left of the aorta at the level of the renal hilum. Dissection was performed along the anterior surface of the renal vein with, if necessary, transection of the tissues with ultrasonic scissors (Figure 5). The left renal vein

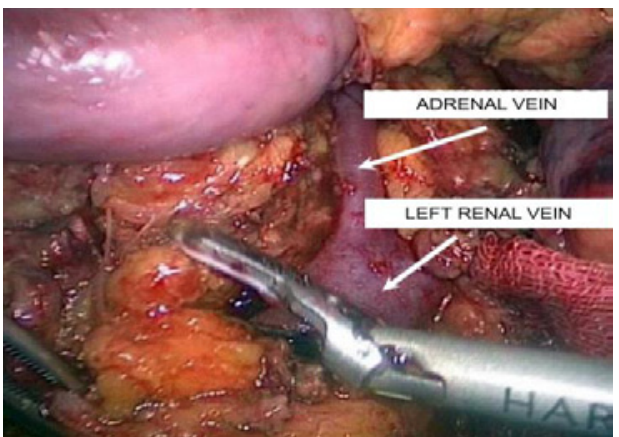

Figure 5: Intraoperative image. Isolation of the renal vein in the retroperitoneal fat.

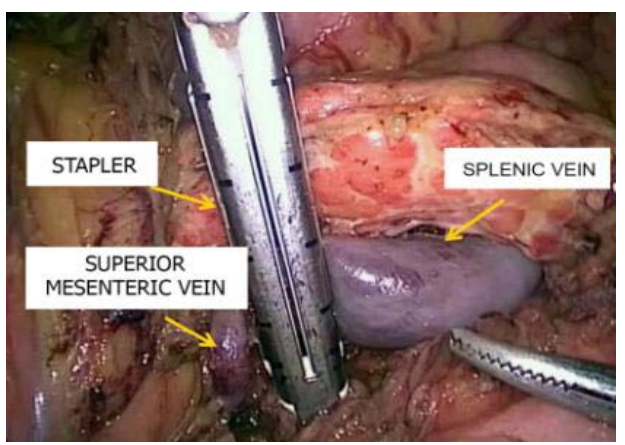

Figure 6: Intraoperative image. Dissecting the splenic vein at the confluence with the superior mesenteric vein with a linear stapler.

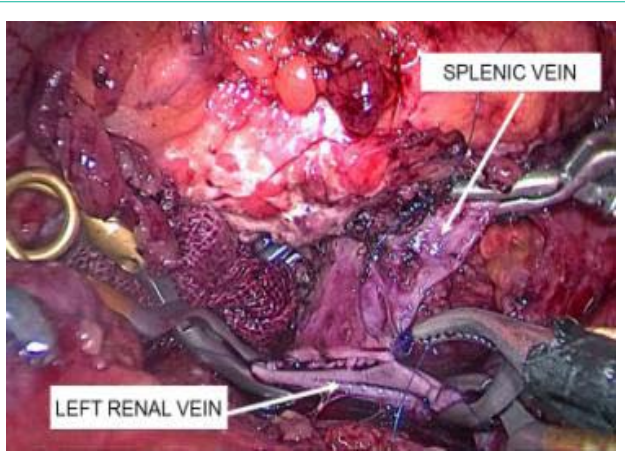

Figure 7: Intraoperative image. End-to-side splenorenal anastomosis.

was mobilized along the entire circumference and over the length sufficient to apply vascular clamps. The left adrenal and left testicular veins were clipped and transected.

After the renal vein was sufficiently mobilized, the splenic vein was transected in the confluence area with the superior mesenteric vein with a linear stapler with a vascular cassette (Figure 6). If necessary, the splenic vein was finally mobilized after transection.

Next, the splenic vein was moved down to the renal vein, avoiding bending at its exit from the tissue of the pancreas. The proximal end of the splenic vein was clamped with a Blalock-type laparoscopic vascular forceps. The same two clamps were applied to the renal vein towards each other. The sutured end of the splenic vein was cut off. A side window was cut out between the renal clamps with scissors to form an anastomosis. The vascular anastomosis was formed end-to- 


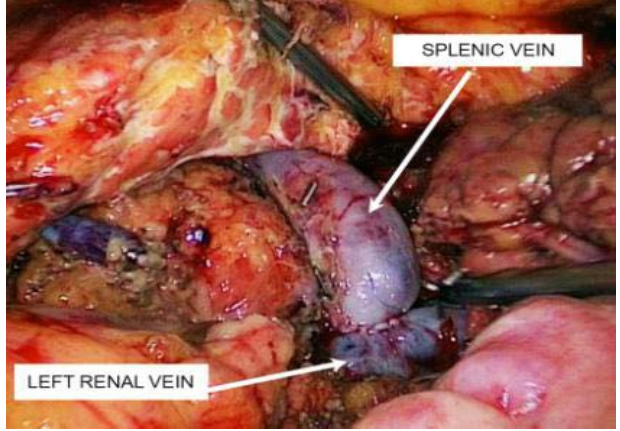

Figure 8: Intraoperative image. Formed distal splenorenal anastomosis.

side with two continuous intracorporeal sutures along the posterior and anterior semicircle with 6/0 synthetic non-absorbable sutures, thereby minimizing the risk of purse string deformity of the vascular anastomosis and shunt thrombosis in the postoperative period (Figures 7,8). During vascular suturing, the clamps on the splenic and renal veins were opened several times to prevent thrombus formation until a distinct blood flow was obtained.

To reduce the arterial splenic blood flow and correct the hypersplenism events, the operation was supplemented with dosed ligation of the splenic artery. The splenic artery was located by a noticeable pulsation along the anterior-superior edge of the pancreas. After peritoneum dissection, the artery was isolated along the entire circumference for $2 \mathrm{~cm}$ immediately after its departure from the celiac trunk. A ligature was applied with a $3-\mathrm{mm}$ instrument. At this, the artery was stenosed by $2 / 3$ of the diameter. Then the stomach was mobilized along the lesser curvature with clipping and dissecting with scissors or stapler- dissecting the left gastric vein and varicose transformed vessels up to the esophagogastric junction. The operation ended with the installation of drains to the anastomotic area and into the pelvic cavity.

The average surgery time was $294 \pm 86$ minutes. The maximum blood loss volume was $211 \pm 55 \mathrm{ml}$. Intraoperatively, bleeding from the pancreatic branches of the splenic vein developed in 3 cases, requiring the approach conversion. In one case, a median laparotomy was performed, in the other two, the operation was completed with the DSRA formation through a minilaparotomic pararectal approach.
It should be noted that this complication and access conversion occurred at the initial stage of the development of the technique. In the postoperative period, the patients were in ICU for 1-2 days $(32 \pm 9.6 \mathrm{~h})$. The next day, the patients were activated. On day 1 , water was allowed; on day 2, liquid food was prescribed. There were no infectious complications or deaths. The inpatient treatment lasted for $9.4 \pm 2.5$ days.

Clinical signs of portosystemic encephalopathy in the early postoperative period developed in 3 (12\%) cases: these were transient and stopped by hepatotropic agents, lactulose preparations and the appointment of a diet with limited animal proteins.

To control the DSRA patency, all patients went through dynamic ultrasound monitoring with an assessment of the main parameters of portal blood flow. Before the operative decompression of portal hypertension, the portal vein diameter was increased to $15.3 \pm 1.4 \mathrm{~mm}$, and the volumetric velocity of the portal blood flow was $985 \pm 287 \mathrm{ml}$ / min (Table 1). In all patients, hepatopetal blood flow through the portal vein was determined. The splenic vein was also dilated from 11 to $16 \mathrm{~mm}$, and the volumetric blood flow was $784 \pm 216 \mathrm{ml} / \mathrm{min}$. In the early postoperative period, there was a slight decrease in the portal vein diameter $(p=0.53)$. However, the reduction in portal blood flow was featured by a noticeable decrease in velocity parameters $(\mathrm{p}=0.009$ and $\mathrm{p}=0.014$ ). at color flow mapping, high-speed turbulent blood flow with a volumetric flow rate of $898 \pm 364 \mathrm{ml} / \mathrm{min}$ was visualized in the lumen of the shunts. In the long-term period, the diameter of the portal vein decreased to $12.1 \pm 1.7 \mathrm{~mm}(\mathrm{p}=0.01)$, though the volumetric blood flow did not significantly change in comparison with the early postoperative period $(\mathrm{p}=0.11)$. Hepatofugal blood flow through the portal vein in the long-term period was recorded in two patients, with a parietal thrombus at MSCT angiography in these observations. The lumen of the vascular anastomosis chamber increased $(p=0.032)$, the blood flow rate through them decreased $(\mathrm{p}=0.02)$ and the flow became laminar. The shunting volume at DSRA in the long-term was $914 \pm 280 \mathrm{ml} / \mathrm{min}(\mathrm{p}=0.067)$. There were no cases of thrombosis of the vascular anastomosis in the early and late followup periods, both according to ultrasound and MSCT data.

Control fibroesophagogastroscopy on days 14-21 showed a decrease in the esophagus VV grade (Table 2). In general, grade III of varicose veins in the early postoperative period was established in $56 \%$

Table 1: Dynamics of changes in the portal blood circulation.

\begin{tabular}{|c|c|c|c|c|c|c|}
\hline \multirow[b]{2}{*}{ Observation period } & \multicolumn{3}{|c|}{ Portal vein } & \multicolumn{3}{|c|}{ Splenic vein } \\
\hline & Diameter, mm & Linear speed, cm/sec & $\begin{array}{l}\text { Volumetric rate, } \mathrm{ml} / \\
\mathrm{min}\end{array}$ & Diameter, mm & Linear speed, $\mathrm{cm} / \mathrm{sec}$ & $\begin{array}{l}\text { Volumetric rate, } \mathrm{ml} / \\
\text { min }\end{array}$ \\
\hline Before surgery & $15.3 \pm 1.4$ & $14.4 \pm 4.3$ & $985 \pm 287$ & $13.3 \pm 2.8$ & $16.6 \pm 5.5$ & $784 \pm 216$ \\
\hline Early postoperative period & $14.3 \pm 0.9$ & $7.16 \pm 1.79$ & $580.05 \pm 188$ & $12.5 \pm 1.7$ & $27.1 \pm 8.6$ & $898 \pm 364$ \\
\hline $\begin{array}{l}\text { Long-term postoperative } \\
\text { period }\end{array}$ & $12.1 \pm 1.7$ & $11.2 \pm 1.67$ & $631 \pm 248$ & $12.7 \pm 2.8$ & $25.5 \pm 9.9$ & $914 \pm 280$ \\
\hline
\end{tabular}

Table 2: Dynamics of regression of varicose veins of the esophagus.

Table 2: Dynamics of regression of varicose veins of the esophagus.
\begin{tabular}{|l|c|c|c|}
\hline \multicolumn{1}{|c|}{ Observation period } & \multicolumn{3}{c|}{ Grade of varicose veins of the esophagus, abs. (\%) } \\
\hline$(\mathrm{n}=25)$ & Grade I & Grade II & Grade III \\
\hline Before surgery & - & $2(8 \%)$ & $15(60 \%)$ \\
\hline Early postoperative period & $1(4 \%)$ & $10(40 \%)$ & $14(56 \%)$ \\
\hline Long-term postoperative period & $6(24 \%)$ & $16(64 \%)$ & - \\
\hline
\end{tabular}


of patients, while grade IV was absent. In the long-term period, in the overwhelming majority of cases, grade I-II varicose veins were seen, while in 3 patients esophagus VV grade III persisted. These patients additionally underwent endoscopic ligation. In the long-term period, the stomach VV grade I was diagnosed in 9, and II degree in 3 cases. There were no cases of gastroesophageal bleeding in both the early and long-term follow-up periods.

The maximum follow-up period was 46 months. All patients are alive, most are capable, socially adapted.

Discussion. Endoscopic ligation is the recommended method for the treatment and prevention of esophageal VV bleeding. This treatment option with minimal invasiveness allows achieving final hemostasis in $86-95 \%$ of cases with the recurrence rate in the early postoperative period of $15-30 \%$. However, relapse of the esophagus $\mathrm{VV}$ in the long-term period is diagnosed in $57-60 \%$ of cases, the progression of varicose veins of the stomach is observed in $18-25 \%$, and recurrence of bleeding during follow-up up to 1 year develops in $10-20 \%$ of patients, which requires re-ligation $[8,10,16-18]$. Endoscopic ligation is practically ineffective in the development of gastric VV bleeding. In these cases, as therapeutic options, it is necessary to consider performing operations of azygoportal disconnection or portosystemic anastomoses in various variants [6$8,19]$.

Azygoportal disconnection surgery is considered less effective than portosystemic shunting. According to the summary data, postoperative mortality when performing operations of this type for emergency indications reaches $21.1-39.3 \%$, and $4.5-13.6 \%$ for routine operations. The $\mathrm{AE}$ rate depends on the degree of hepatic decompensation: it is $15-25 \%$ at subcompensated cirrhosis, rising to $47-65 \%$ in patients with decompensated liver function. Supplementing the esophagus and stomach VV stitching of the with the spleen removal increases postoperative mortality by 1.5 times. The esophagus VV regression is observed only in $76 \%$ of patients and only in the period of up to 6-12 months. Relapse of bleeding in the late period develops in 45-52.3\% of cases [8,20-25].

Transjugular Intrahepatic Portosystemic Shunting (TIPSS) is a minimally invasive endovascular intervention that provides rapid decompression of the portal system and is effective not only in the treatment and prevention of bleeding from the esophagus and stomach $\mathrm{VV}$, but also in the treatment of ascitic syndrome. However, mortality in TIPSS ranges from 4 to $29 \%$ and is determined by the timing of surgery (for urgent indications at the height of bleeding and routinely to prevent bleeding) and the severity of hepatic dysfunction. In the long term after TIPSS, the incidence of shunt stenosis/thrombosis reaches $18-62 \%$, and post-shunt encephalopathy develops in 20-46\% of patients. Transjugular intrahepatic portosystemic shunting is not possible with portal vein thrombosis. In Russia, due to its high cost, the need for special equipment and high qualifications of a specialist, TIPS has a limited application today $[4,5,7,10,26]$.

In patients with compensated and subcompensated liver function, DSRA is an effective method of treatment and prevention of esophagogastric bleeding of portal genesis. This anastomosis provides selective decompression of the gastroesophageal basin, reliably prevents recurrence of bleeding from the esophagus and stomach
$\mathrm{VV}$, is featured by a low incidence of shunt thrombosis (3-11\%). Relapse of bleeding in the early postoperative period develops in 5-12 $\%$ of cases. The frequency of post-shunt encephalopathy after surgery, according to various sources, ranges within $10-22 \%[4,8,9,11,25,27$ 30].

Thus, DSRA is superior to TIPSS in terms of its efficacy and complications rate. Its significant disadvantage is the intervention invasiveness, mainly due to the laparotomic approach. The aim of this study was to assess the feasibility and efficacy of the laparoscopic approach DSRA.

In the foreign medical literature of the past 30 years, there are only two publications devoted to the possibility of endovideosurgical performance of portocaval bypass grafting. In 1999 F.C. Desmaizieres and A. Bobbio were the first to report on the possibility of performing a laparoscopic partial portocaval $\mathrm{H}$-anastomosis [31]. In 2015, a group of surgeons led by $\mathrm{U}$. Boggi presented the results of a robot assisted DSRA [32].

As a result of the present study, it was found that in most cases $(89.3 \%)$, the isolation of the splenic and left renal veins and intracorporeal formation of the vascular anastomosis is possible during laparoscopic intervention (RF patent for invention No. 2624812, Method of laparoscopic distal splenorenal anastomosis with ligation of the splenic artery and devascularization of the stomach in portal hypertension; Kotiv B.N., Dzidzava I.I., Ivanus S.Ya., Onnitsev I.E., Smorodsky A.V., Slobodyanik A.V., Soldatov S.A., application no. 2015150780, dated 06 July 2017). The laparoscopic DSRA forming technique did not affect the treatment results. The average surgery time was $324 \pm 86$ minutes, and that of inpatient treatment $-9.4 \pm 2.5$ days. There were no lethal cases, no cases of gastroesophageal bleeding and shunt thrombosis. The portosystemic encephalopathy rate was $12 \%$. Surgical decompression of the portal system was featured by a decrease in the esophagus VV grade in the long-term period.

Conclusion. Performing the distal splenorenal anastomosis with a minimally invasive laparoscopic technique in patients with portal hypertension syndrome is a feasible, safe and effective alternative treatment option. Reducing the invasiveness of the intervention helps to shorten the time the patient spends in the intensive care unit and reduces the total bed-day number in the absence of shunt thrombosis, recurrent bleeding from varicose veins of the esophagus and a low incidence of post-shunt encephalopathy in the early and late postoperative periods.

\section{References}

1. D'Amico G, Pagliaro L, Bosch J. The treatment of portal hypertension: a meta-analytic review. Hepatology. 1995; 22: 332-354.

2. Chalasani N, Kahi C, Francois F, Pinto A, Marathe A, Bini EJ, Pandya P, et al. Improved patient survival after acute variceal bleeding: a multicenter, cohort study. Am J Gastroenterol. 2003; 98: 653-659.

3. de Franchis R. Revising consensus in portal hypertension: report of the Baveno $\mathrm{V}$ consensus workshop on methodology of diagnosis and therapy in portal hypertension. J Hepatol. 2010; 53: 762-768.

4. Lo G-H. The use of Transjugular Intrahepatic Portosystemic Stent Shunt (TIPS) in the management of portal hypertensive bleeding. J Chin Med Assoc. 2014; 77: 395-402.

5. Herrera JL. Management of acute variceal bleeding. Clin Liver Dis. 2014; 18: $347-357$. 
6. Rajoriya N., Tripathi D. Historical overview and review of current day treatmen in the management of acute variceal haemorrhage. World J Gastroenterol. 2014; 20: 6481-6494.

7. Satapathy SK, Sanyal AJ. Nonendoscopic management strategies for acute esophagogastric variceal bleeding. Gastroenterol Clin North Am. 2014; 43: 819-833.

8. Mercado MA. Surgical treatment for portal hypertension. BJS. 2015; 102 717-718.

9. Henderson JM, Boyer TD, Kutner MH, Galloway JR, Rikkers LF, Jeffers LJ, et al. Distal splenorenal shunt versus transjugular intrahepatic portal systematic shunt for variceal bleeding: a randomized trial. Gastroenterology. Jason Connor DIVERT Study Group. 2006; 130: 1643-1651.

10. Zatevakhin II, Tsitsiashvili MSh, Shaginyan AK, Monachov DV, Myznikov IV Distant results of endoscopic ligation of varicose veins of the esophagus in patients with liver cirrhosis. Vestnik RGMU. 2010; 2: 18-21.

11. Orloff MJ, Vaida F, Haynes KS, Hye RJ, Isenberg JI, Jinich-Brook H. Randomized controlled trial of emergency transjugular intrahepatic portosystemic shunt versus emergency portacaval shunt treatment of acute bleeding esophageal varices in cirrhosis. J Gastrointest Surg. 2012; 16 2094-2111.

12. Pugh RNH., Murray-Lyon IM, Dawson JL. Transsection of the oesophagus for bleeding oesophageal variceas. Brit J Surg. 1973; 60: 648-652.

13. Paquet KJ. Sclerotherapy for the prevention of bleeding esophageal varices. Internist (Berl). 1983; 24: 81-84

14. Binmoeller P. Treatment of esophagogastric varices. Endoscopy. 1996; 28 44-53.

15. Podymova SD. Liver disease: manual. $-4^{\text {th }}$ edition revised and enlarged Moscow publishing house «Medicina». 2005; 768.

16. Troillet FX, Halkic N, Froehlich F, Moradpour D, Gonvers JJ, Denys A. Complication of liver cirrhosis: oesophageal varices, ascites and hepatocellular capcinoma Rev med Suisse. 2005; 1: 249-255.

17. Chen WC, Lo GH, Tsai WL, Hsu PI, Lin CK, Lai KH. Emergency endoscopic variceal ligation versus somatostatin for acute esophageal variceal bleeding. J Chin Med Assoc. 2006; 69: 60-67.

18. Scherzinger AG, Zshigalova SB, Musin RA, Demyanov Al, Abdullaev ICh. Complications of endoscopic procedures in patients with portal hypertension. Annaly khirurgicheskoy hepatologii. 2007; 12: 16-21.

19. Jiang GQ, Chen P, Qian JJ, Yao J, Wang XD, Jin SJ, Bai DS. Perioperative advantages of modified laparoscopic vs open splenectomy and azygoportal disconnection. World J Gastroenterol. 2014; 20: 9146-9153.
20. Orozco H, Mercado MA, Chan C, Ramos-Gallard G, Gálvez-Treviño R, Salgado-Nesme N, et al. Current role of surgery for the treatment of portal hypertension. Ann Hepatol. 2002; 1: 175-178.

21. Ma YG, Li XS, Zhao J, Chen H, Wu MC. Modified Sugiura procedure for the management of 160 cirrhotic patients with portal hypertension. Hepatobiliary Pancreat Dis Int. 2004; 3: 399-401.

22. Anisimov AU, Kuznetsov MV. Bleeding from varicose veins of the esophagus and stomach in patients with portal hypertension Annaly khirurgicheskoy hepatologii. 2005; 10: 71

23. Kitsenko EA, Zavorotnaya EK, Abdullaev ICh. Results of the M.D. Patsiora operation in patients with liver cirrhosis and portal hypertension Annaly khirurgicheskoy hepatologii. 2005; 10: 80.

24. Xu X-B, Cai J-X, Leng X-S, Dong J-H, Zhu J-Y, He Z-P, et al. Clinical analysis of surgical treatment of portal hypertension. World J Gastroenterol. 2005; 11 : 4552-4559.

25. Nazirov FG, Devyatov AV, Ibadov RA. Long-term results of total disconnection of the gastroesophageal collector in patients with portal hypertension. The First International Conference on Thoraco-Abdominal Surgery on the Occasion of the $100^{\text {th }}$ Anniversary of Academician B.V. Petrovsky: abstracts. Moscow. 2008: 177.

26. Qi XS, Bai M, Yang ZP, Fan DM. Selection of a TIPS stent for management of portal hypertension in liver cirrhosis: An evidence-based review. World J Gastroenterol. 2014; 20: .6470-6480.

27. Wong LL, Lorenzo C, Limm WM, Wong LM. Splenorenal shunt: an ideal procedure in the Pacific. Arch Surg. 2002; 137: 1125-1129.

28. Ellwood DR, Pomposelli JJ, Pomfret EA, Lewis WD, Jenkins RL. Distal splenorinal shunt: preffered treatment for recurrent variceal hemorrhage in the patient with well-compensated cirrhosis. Arch Surg. 2006; 141: 385-388.

29. Livingstone AS, Koniaris LG, Perez EA, Alvarez N, Levi JU, Hutson DG. 507 Warren-Zeppa distal splenorenal shunts a 34-year experience. Ann Surg. 2006; 243: 884-894.

30. Santambrogio R, Opocher E, Costa M, Bruno S, Ceretti AP, Spina GP. Natural history of a randomized trial comparing distal spleno-renal shunt with endoscopic sclerotherapy in the prevention of variceal rebleeding: a lesson from the past. World J Gastroenterol. 2006; 12: 6331-6338.

31. Desmaizieres FC, Bobbio A. The world's first: laparoscopic portocaval H-graft shunt. J Chir (Paris). 1999; 136: 333-340.

32. Boggi U, Belluomini MA, Barbarello L, Caniglia F, Brunetto M, Amorese G. Laparoscopic robot-assisted distal splenorenal shunt. Surgery. 2015; 157: 405. 